\title{
例析情境教学在初中英语课堂中的使用对策
}

麻少红

青岛莱西第四中学

DOI:10.32629/jief.v2i5.1446

[摘 要] 在现如今的新型教学法中, 情况教学法的应用次数最多。因为情景教学法需要的辅助工具不多, 教师只要根据知识点创设有关情境, 让学生进行探索就可以了。英语是语言学科, 但是颠覆了学生长久以来养成的语言习惯, 学生学习起来有一定的困难。根据实践数据来看, 有效创设情境可以将学生带入英语语言思考状态, 并根据所学总结出如何应用英语, 有效的提高学生的思维能力和应用能力。本文从"利用问 题情境激发学生英语思维"'利用生活情境培养学生语感"'利用趣味情境培养学生兴趣"例析了情境教学在初中英语课堂中的使用策略。

[关键词] 初中英语; 情境教学法; 应用策略

中图分类号: G633.41 文献标识码: A

初中生虽然有了一定的学习基础, 但是正处于青春期的过渡期, 在 学习过程中还保留着以前的习惯, 比如: 注意力无法长时间集中, 学习意 识较为薄弱等等。有句老话叫做”兴趣是学生最好的老师”, 若是学生对 英语学生不感兴趣, 那么学习效果就会不理想, 学生也无法进行自主学 习。情境教学法将新课改理念当做了教学基础, 通过环境将学生的学习 情感激发, 让学生对学习产生兴趣, 从而提高教学质量。

\section{1 利用问题情境激发学生英语思维}

问题情境就是在教学过程中以问题为主, 通过层层递进的问题引导 学生进行学习。在问题情境教学中, 学生的思维一直呈现活跃状态, 也 会积极思考英语知识的应用方法。受传统教学的影响, 在教学过程中学 生养成了很多不好的学习习惯, 并且丧失了主动思考的能力, 只知道记 笔记、死记硬背, 这些知识要应用到什么地方, 什么时候要说什么样的 英语学生一概不知。之所以创设问题情境, 就是为了摆脱这一现状, 让 学生在情境中理清思路, 逐渐掌握学习的方法, 英语思维也能有效得到 激发。

例如在教学”When is you birthday" 的时候, 教师可以将本班学生 的生日活动照收集起来, 然后将其制作成影集利用多媒体技术呈现在学 生面前。看到这些照片, 学生会不自觉的回想起当时过生日的情境, 在 课堂上也会积极的将自己生日会的经历进行叙述。然后教师可以引入课 堂内容, 以”when is you biethday"为题, 让学生互相进行询问回答。 因为这是英语课堂, 之前没有掌握英语回答方式的时候学生都是以汉语 回答的, 这时学生的求知欲极其旺盛, 教师适当的引入重点知识, 不仅 可以达到教学目标, 学生还掌握了应用的方法。

\section{2 利用生活情境培养学生语感}

知识来源于生活也应用于生活, 英语本就是一门语言学科, 学习的 目的就是为了交流沟通和表情达意, 在生活中的应用自然不会少。但是 在中国一般交流用的是汉语, 学生在实际生活中很少会用英语去交流, 学生即便掌握了知识也不知道该怎么应用。因此, 在教学过程中, 教师 需要创设生活情境。一来可以拉近知识与生活的距离, 二来学生在生活 情境中掌握了应用知识的方法。只有在生活情境中直接教学, 学生才能 通过练习形成语感, 才能将英语知识掌握的更加透彻。

例如在教学”Do you 1ike bananas”的时候, 教师可以利用多媒体技 术将学生常见的食物呈现在学生面前, 然后指着相关食物让学生掌握英
语单词, 比如 bananas, hamburgers, ice cream, chicken 等。然后教 师可以将常用对话制成绘本, 通过学生所熟悉的动漫人物引导学生进行 学习, 比如从人物的表情判断是否喜欢某个食物。在学生掌握了单词和 句型后, 教师可以引导学生进行角色扮演, 让学生根据所学内容编写剧 本, 然后模仿动漫人物的语气和神情进行对话。这样一来, 学生既可以 掌握相关知识, 还发现了名词单复数的变化规律。

\section{3 利用趣味情境培养学生兴趣}

相较于枯燥乏味的课堂, 学生更喜欢充满趣味性, 生动活泼的学习 氛围。趣味情境是基于学生的心智创设的情境, 目的是培养学生的学习 兴趣。在教学过程中, 教师可以利用趣味情境, 将学生的学习热情调动 起来, 逐渐帮助学生树立自信, 发现学习的乐趣和自己的长处。不过在 创设趣味情境的时候, 教师要注意趣味性和教育性的均衡, 只有将两者 放在同样重要的位置, 才能激发学生的兴趣、启迪学生的思维。

例如在英语教学中, 记忆单词一项是教学难点。教材中的单词多而 杂, 学生的记忆周期有限, 每天的英语课堂也在传授着全新的知识, 学 生只能不断的重复记忆, 加深对单词的印象。不过这样的方式太过枯燥 乏味, 学生极易丧失学习兴趣。因此, 教师可以创设趣味情境一一游戏 情境, 将学生的学习兴趣激发。在记忆单词的时候, 教师可以引入”看词 比划”的方式, 让学生根据卡片上的单词进行比划, 让其他学生猜单词。 在玩乐的同时, 学生记忆了单词, 口语表达能力还得到了锻炼。

\section{4 结语}

在新课改背景下, 多种多样的新型教学方式出现在课堂教学中, 情 境教学法以简便高效逐渐成为了备受关注和广泛使用的教学方式。学生 受环境影响习惯了汉语的思维方式与表达方式, 情境教学法可以有效突 破学生的思维, 达到教学目标。教师在创设情境的时候, 要注意结合学 生的认知特点和学习情况, 只有这样, 才能提高教学质量。

\section{[参考文献]}

[1]逢维薇.在初中英语课堂教学中培养学生核心素养策略研究 [J]. 新课程,2020(37):43.

[2]兰娟. 初中英语教学中如何构建智慧课堂的策略探究 [J].新课 程,2020(37):147.

[3]林信义. 初中英语课堂情境导入的设计及应用[J]. 名师在 线,2020(24):6-7. 